\title{
Walter Whitman, Bíblico, Futurista Poeta de América
}

(1819-1892)

Detrás de todo adiós se oculta, en parte, el saludo de un Comienzo nuevo. Yo no hago más que escribit una o dos palabras fututistas.

Me limito a adelantarme un instante para tetornat de prisa a las tinieblas.

WALT. WHITMAN

CUANDO Armand Vasseur afirma que algunos de los poemas de U Whitman parecen hechos por la mano que escribiera, el Bhaghavad Gita, o que es una reencarnación de Kalidassa, evade la otra reminiscencia del poeta de Long Island: la persa. $Y$ se ven también contornos del Ramayana; del vahimikio golpe sobre canteras sectlares, sólidos relieves en la religiosa formación de estructuras nuevas sobre cimientos de edades babilónicas -o de pristinas rondas indostánicas- en la bíblica expresiva conformación.

Los hombres de hoy hemos andado buscando en contornos del presente nuevas líneas para expresar vigorosidad que ya poseemos. Los hombres que extraviamos el porvenir, quisimos ver un hallazgo en la gradería metafórica deshumanizada de Tomaso Marinetti, porque ignoramos que, desde antes, ya estaba fijado el futurismo: que viene con nosotros, que está con la humanidad, mejor expuesto; pero que precisa momento creador para enseñarlo a la pupila ecuménica. Ese momento lo halló Walter Whitman, ente que vino a 
la vida terrenal en Long Island, al ruido de un torno de carpintería, el último de mayo de 1819.

Fondo y forma vigorízalos el aliento de este hombre que rompió moldes encasilladores de fuerzas, que deshizo el treno bíblico, para romperlo al golpe de Sansón; que interfirió en el cosmos con sus dominaciones cerebrales, y que de un salto se situó en la plataforma de futuros en obstrucción constante de lo pasado.

Los émbolos en que afiébranse instantes y dias y tiempo, para movilizar energías, son sus émbolos. En fornicación constante empuja maquinarias. Su aliento es de númenes saturados de poderío, y de ahí que su canto no sea sino demolición de lo pasado y actuación de perpetuos presentes, trascendiéndolos por los rumbos de la vida desde un presente hominal: presente donde el hombre actúa potencialmente. Su grito repercute en los hondos abismos del Más Allá; y su rememoración urge plasticidades, realiza nóumenos y fenomeniza circunstancias líricas, en un lirismo desbordante en equilibrio, grandeza y panteísmo en la religiosidad positiva de su fuerza creadora :

Yo, el poeta de los Cantos Adámicos,

Desbordante de vida; fálico, poseedor de potentes $\mathrm{y}$ originales

Riñones, perfectamente puro,

Indestructible, inmortal, retorno a través de las edades.

Lo que es pequeño, lo hace grandioso; lo que es grande, lo ensancha y lo empuja llevándolo a dominios por donde nace la Vida, que crea nuevas formas y nuevas contiendas y nuevos ruidos $y$ nuevas cataratas, en el mismo futuro, presente de todas las edades.

Confieso que en mi largo trajinar por libros; libros y libros de distintos climas y que han pasado tejiendo diferentes panoramas ante mis ojos, jamás había contemplado arquitecturas como la de este americano que viene quién sabe desde qué siglos tramontando oleajes sobre el tiempo para temporalizarse en el siglo diez y nueve, en un país de estropajos, rotundamente trepidante, y en donde un William James quiso filosofar "a la manera" de quien -en contradicción de su verdadero vigor- puso nombre simple al contenido de su médula; nombre simple al libro por el que entrara a las trascendencias de la lírica mundial: Hojas de hierba. iHojas de hierba! y iqué hierba! $\mathrm{Y}$ si esto era la fronda de eso que creemos 
minúsculo, a ras de tierra, ¿ cómo serían los árboles de este hombre que aun paralítico, adoquinado en su silla, viendo desflecarse las risas del viento norte sobre la mar encrespada, estaba golpeando con los aldabones en las puertas de la Eternidad?

Porque Hojas de hierba se contradice con la substancia del pensamiento whitmaneano. $Y$ cualquiera engañaríase pensando que iba a leer y a sentir una égloga de ambiente virgiliano, o una elegía de Frandais o lucubraciones de Ronsard, o afrancesamientos becquerianos; mas se halló con un super-humanismo que bifurca aspectos de lo existencial, anchurosamente unido por eslabones indestructibles. Dice:

"Para mí, el Desarrollo, la Continuidad, la Inmortalidad, la Transformación, constituyen los temas y las significaciones capitales de la Naturaleza y de la Humanidad."

En lo anterior está clavado, inamovible, sobre puertas de templos estéticos y empotrado en murallas de cualesquiera edades un principio de Eternidad y de Verdad; de esa verdad que demarca evoluciones ocultas y visibles; pero que determina situaciones no sólo del hombre sobre la tierra sino que más allá de ella en las hiper-esferas que no puede abarcar la mente.

Whitman no es celestial por su esencia; pero es superhumano a fuerza de ser terrestre con sus posiciones proyectadas en médula evolucionada y evolutiva. Fálico, vibrando en creaciones; equilibrado, no se aparta un instante de su posesiva cualidad ecuménica. Las imágenes poco le sirven porque ha desvestido de sarmientos el vocablo para presentar desnudas las frases, solamente con el poder correlativo que éstas tienen cuando están acondicionadas firmemente en representación —o re-creación - de aspectos de la naturaleza.

No hace contorsiones con palabra's para escurrir ideas en intersticios malabares, como los "futuristas" y otros "istas" de hoy que se cuelgan de barrafijas metafóricas para ver si pueden entretener la atención del que los lea y enredarlo con frases de clown que, en realidad, éstas promueven a risa en el circo de los trampolines figurativos.

Por lo tanto, no cae Whitman bajo la sanción del muy apreciado Voltaire, quien asegurara que los poetas eran "mentirosos, por no decir ridículos", afirmando Oliver Belmás que ser gran poeta es ser gran embustero. 
$\mathrm{Ni}$ ridículo, ni embustero, ni embaucador, ni insincero. Walter Whitman ha legado a la humanidad el verbo positivo que rige las acciones del hombre. Ha dado el toque vicentino y razonable con sus clarines previsores. Ha extendido su Razón de Vida por ambientes en que fué acumulando energías para presentarse ante el futuro, dominador y creador, engendrando continencias en que deben permanecer vivas fuerzas acopladoras de células puras, verdad pura, calidad pura.

Tomara el Atma-Budhi-Manas en sus manos y exprimiéralo en el verbo aventándolo al tiempo, llevando gérmenes a que fecundaran en sementeras donde cayeran. Potente en cuerpo y en alma, la aniquilación no existe para sus músculos. Antítesis del aristo griego, sin dejar de tener un apenas, el demos de su complexión extiéndelo de modo que traspasa cánones y descarga energías orientadoras, plenas de vida en la realidad de las cosas y de las almas:

Soy el poeta del Cuerpo y el poeta del Alma, Los placeres del Cielo me acompañan, me acompañan las torturas del Infierno: He multiplicado en $\mathrm{mi}$ el injerto de los primeros, Los segundos los traduzco en un idioma nuevo.

"Soy el poeta del Cuerpo", asegura; mas no sólo el cuerpo de carne, de esta carne que nos asesina limitándonos. Es el cuerpo en que se expresa la vida, es el cuerpo de cuerpos, múltiple; el cuerpo universal; lo que palpamos y vemos y sentimos. $E$ igual cuando clama: "y el poeta del Alma", porque está en las esencias y porque conoce los íntimos secretos en donde Dios está dirigiendo pautas para las formas. Trascendido al cosmos, inquiere en el "adelante" del tiempo y en el del espacio para retornar a él, al Poeta, a su mundo íntimo, absoluto -en lo que de absoluto hay en él-y que le da visión de lo que existe afuera y dentro de él. Conoce de las transmigraciones, comprende que viene y que va, y que el presente adámico está fijo. Pleno de conocimiento:

Existo tal cual soy, eso me basta,

Si nadie lo sabe, eso tampoco amarga mi satisfacción, $Y$ si lo saben todos, igual es mi satisfacción.

Lo sabe un mundo -el más vasto de los mundos para mi-, Que soy yo mismo. 
Y llegaré a mis fines, hoy mismo, o dentro de diez mil

Años o después de diez mil millones de años.

Hemos llegado a la profunda convicción del Poeta (egolatría. dirían muchos). Tramontado por impulsos deíficos, por naturales fuerzas volitivas, por ese Poder genésico que impele hombres, formas y edades, sabe que él permanece en las épocas y tiempos, aunque no sea en forma, sino en esencia; mas debe llegar a ese Punto a que todos los humanos tienen que llegar para incorporarse a lo $\mathrm{Ab}$ soluto, a lo Unico. El hoy del poeta, espiritual, es el ayer. ¿Y la figura? Producto de una disposición para ejercer atributos en cuerpo formal en esta esfera mundana por lo que él expone que aunque llegue dentro de diez mil milones de años, "puede aceptar ahora su destino con corazón alegre o esperar con igual alegría".

$\mathrm{Y}$ aquí está la substancia de su comprensión, de su honda comprensión de Vida, de sus dones, de sus energías y de su calidad existencial.

$\mathrm{Y}$ allá, en lo expuesto anteriormente, vibra el fundamento deífico de su poesía: espíritu de esta poesía ciclópea, fornida, con fornidez de mazo que tritura aceros; mazo de idea sobre el yunque de la palabra, discrepando con lo que es bajo; pero elevando lo que ha sacado del fondo de miasmas en que germinan las más bellas flores y de donde salen las más atrayentes fulguraciones pentipetálicas.

Alguien ha querido hacer paralelo entre Whitman y Nietzsche; mas no existe sino en el apersonamiento al nihilismo; pero lejanamente, puesto que el nihilismo de Whitman no tiene ubicación definida, ni posee sistema como el del Superhombre. Su nihilismo es de movilización, de ir y de venir, de migrar y volver, de asegurar que hay una fuerza de donde dimanan energías y de afirmar -igualmente - que esas mismas fuerzas son nada. Increpa:

Qué es un hombre después de todo? Qué Sois? Qué Sois? Que el tiempo y la nada son sinónimos, que la tierra no es más (que podredumbre.

$\mathrm{Y}$ siendo podredumbre, digo yo, ya existe un ES, en ese concepto de tierra aunque las interrogaciones se cierren en la duda que aguijonea esfuerzos para declinar en razones a veces irrazonables, pero razones. 
El antecedente de Whitman en su panteismo, no lo podemos encontrar, definido, en Spinoza y menos en Darwin. Quizás se remonta a pretéritas funciones, a los poetas védicos, o al Gautamismo que diseñó esquemas esenciales para futuros contradictorios en el futuro de la humanidad.

En futuro se mantuvo el bardo de Long Island, representando su papel. Forcejeando por evadirse de su prisión, de esta prisión sentimental; permanecía en ella, de tal modo que, aunque $\sin$ hacer alarde de sus sentimientos melancólicos escritos que rechazaba Stendhal, se iba por el opuesto, porque fué vigoroso en su atletismo ideológico: fuerte. No con la fortaleza corporal de Gautier, quien elogiaba su musculatura, tanto como a su poesía, vanagloriándose de sus bíceps, los que mostraba con vanidad; con más vanidad que cuando enseñara un poema.

Whitman no fué artista esencialmente fino, ni detúvose en burilar detalles ideológicos o formales. Trató él de ser lo menos posible un artista. Fué hombre que se expandía por sobre lo que abarcara su poder creativo. Cuasi natural en sus exposiciones, entendió que se debe ir desnudo, sin artificios, sin impostura, con la verdad viva en el alma y en el corazón y en el cuerpo y en la existencia, comprendiendo que cuanto menos se artificialice el hombre es más natural en su expresión. Fué cerebral.

(Si Montaigne preceptuara que al naturalizar el arte se artificializa a la naturaleza, más se artificializa el hombre al desnaturalizar sus facultades, siendo como es conjunto cuasi perfecto de la naturaleza. Y... en estos momentos, con persistencia increíble, el artificio predomina más que en ninguna otra época. Búscase negativamente naturalidad pretendiendo darla quienes tratan de cubrir origenes, poniéndole guantes de hierro al alma y máscaras gesticulantes a las expresiones físicas. El ángel rebelándose contra su Dios para caer en grosera maléfica materia.)

Whitman, posesionado de su centro potencial, proyecta su fisonomía sobre la humanidad que llega.

$\mathrm{Y}$ bien: siendo el profeta de lo que hoy denominamos Futurismo; siendo el Juan Bautista de lo Ultramoderno así llamado, ¿ puede verse la consistencia de sus texturas expresivas, en la formalidad de las frases? 
Como todo hombre que se adelanta (Juan de Pathmos que mird a través de siglos lo que llegará para los hombres), expuso naturalmente su cuerpo.

La rima fué desalojada por él del lugar que le daban los artífices. El vocablo sufrió transformación y el ritmo tuvo pendulaciones rudas, de bucéfalos en desórdenes por llanuras soleadas. La métrica quedó relegada al sistema y el canon estético fué rechazado en cuanto a tiempos y medidas, compases y concentos; pero no destrozó este hombre la armonía, ni menos la lógica y mucho menos atrapó imágenes para retorcerlas en enredaderas metafóricas. Si rotundo, claro; si claro, haciendo del lenguaje ( $y$ hay que agradecerle mucho a sus traductores Vasseur, Maristany, Rioseco y otros) camino seguro para que no se perdieran los que fueran a él. Sí, destruyendo lo establecido en verso, por lo que su clasicismo hirió el concepto de quienes no podían avenirse a una ruta por donde nadie había antes pasado en quién sabe cuántos siglos.

¿Son versos los de Whitman? No. Porque el verso tiene su estructura definida, su meticulosa formación, su andar con paso lento, rápido o ágil, del que no puede salirse la figuración: reglas. Amétrico y arrítmico, despedazó carriles y se quedó con el ritmo que inyectó de vigor: púsole médula de estruendo, e hizo relampaguear en el Sinaí de su palabra, el índice con que se escribiera el multicálogo de lo llamado actualmente "Futurismo".

Si Vargas Vila, si José María Vargas Vila, tomó de lo bíblico únicamente lo calológico y redobló atambores en adjetivaciones intermitentes y tronó con su reconocida pujanza verbal ideológica contradictoria, el demócrata Whitman, si no encendió sus estrofas con el fuego hebraico, atronó con su ritmo, quiso verse a través de las edades y atraparse para colocarse en este siglo pasado, proyectándose desde entonces sobre los siglos venideros.

De aquí, del vientre de este pelícano que a orillas de las aguas que bañan a Manhattan, mirara de frente al sol, salieron los que hacen jerigonzas, los seguidores del Marinetti que quiso desbaratar las vírgenes de las rocas, como si ellas no estuvieran alli bajo el manto de D'Annunzio amparándose del vendaval acribillador, viendo cómo pasa el infinito junto a ellas; de los seguidores de Apollinaire y Cocteau y Jacob y otros; de los que buscan erguirse haciendo contorsiones y extraviando en veredas el sentimiento. Porque Mari- 
netti y los otros, al querer desplazar, hollaron el terreno en que ya había estado dignamente Walter Whitman a quien le deben -le debemos mucho- los que hemos creído en la fortaleza del alma y no en las inútiles lamentaciones.

De Whitman tomaron las formas, y las deformaron, queriendo ser más originales que quien tampoco lo fué, porque no hizo más que parecer por Aqui, to que había sido Allá. Es la reminiscencia platoneana que estaba hundida en el alma de Whitman, suficientemente comprendida por él.

Los futuristas de hoy, revientan piedras y astillan los vitrales que cubren la capilla de los cristos metálicos del paralítico de Long Island. Cuando se destrozan las reglas -asegura Feijóo- es para superarlas; pero no ha habido superación sino desequilibrio en los seguidores de Marinetti. Y si no, veamos la diferencia en to que a formas se refiere, ya que en lo ideológico no pueden equipararse los istas de ahora con Whitman. $\mathrm{Y}$ copio lo denominado verso, y que fuera uno de los tomados en cuenta cuando se premiara a un barrafijista de por allá, en el año 1931. Es de Folicaldi lo que va transcrito y se denomina "Ritmo nuevo":

\footnotetext{
Enarbolar enarbolar enarbolar banderas de orgullo

Vamos vamos vamos por la línea gramofónica del octubre violado

Derrengamiento en los átomos en la partitura

Del cosmos

Pendientes pendientes pendientes de lo efimero

Solbre anchuras de bengala

Tres gotas de azul postmeridian

Sinfonismos blancos.
}

Es un acertijo inextricable lo anterior. Un logogrifo fuera de aspectos entendibles para el que no esté acostumbrado a intróducirse en estos vericuetos. $\mathrm{Y}$ queda para el lector descifrar ese "poema" futurista de Folicaldi seguidor de Marinetti. Pero... voy a mostrar el patrón; voy a enseñar de dónde tomó Marinetti - no los Farfa y otros - el agua de esa fuente que brotó de la roca whitmaneana; que Whitman sí, quebró reglas para superarlas, para superarse en personalidad, para liberarse, porque no eran para él las cárceles forjadas por estéticas fijas. $Y$ aquí va fragmento de un "Canto a una locomotora": 
Belleza de voz feroz!

Rueda a través de mi canto con toda tu música salvaje,

Con tus linternas oscilantes en la noche,

Con la risotada de tus locos silbatos que retumban despertándolo todo a semejanza de temblor de tierra;

Nada más completa que la ley que te rige, ni más recta

a pesar de sus curvas que la via que sigues;

(La bonachona dulzura no es para ti, ni el lloriqueo de las arpas, ni las tonterías de los pianos).

Tus trinos de penetrantes gritos, las rocas y las colinas te los devuelven.

Los lanzas más allá de las vastas praderas, a través de los lagos,

!Hacia los cielos libres, desenfrenados, gozosos y fuertes!

¿Hay comparación siquiera, entre ésto y aquéllo? Sólo en lo que concierne a la libertad (libertinaje en los otros) de aventar su voz de locomotora, su voz de maquinización, parte de ese cuerpo que afirma el poeta es él; así como también canta el alma, siempre en voz de tempestades.

Es Whitman depósito del que tomaron aceite estos de hoy para tirarlo desintegrado y corrompido. La industrialización llegó al iconoclasticismo, retorció a la misma anarquía y se despedazó en retortijones de palabras, indigestando ideas y triturando el sentido legible.

Sin savia el concepto y sin médula la palabra, no queda sino un embarazo de vocablos.

Deformada así por los futuristas de hoy la estructura poética de Whitman, éste permanece consolidado en su textura arquitectural, hecha con himnos a la fuerza evolucionadora. Porque su canto no es canto, es trepidación de un himnario férreo que se extiende potencialmente por el ambiente mundial. Himnos de tempestad en que el viento lleva un coro de voces motorizadas: coro preconizador de la maquinaria; como también ese mismo viento emptija psalmos a la naturaleza que fecunda vientres en constante emanación de poderío.

Coro de voces potentes, de voces de émbolos y de motores, como de oleajes golpeando contra rocas que expectan en los mares todos de lo infinito.

Los que hallaron en Whitman la veta, perdiéronla. Si éste deshizo el verso para atenerse al ritmo y a la lógica, aquellos rompieron 
hasta la sintaxis. No basta el decir los pensamientos sin ningún ritmo y sin ningún orden, ese orden que existe hasta en la misma naturaleza que sitúa en climas apropiados sus entes, con esa sabiduría del Gran Espíritu que conoce en dónde debe vivir el pez y en dónde la musaraña y el cóndor, dándole poderes al hombre - producto casi perfecto de ella - para que vaya por diferentes rumbos con la libertad relativa de que goza. No sólo aniquilaron tal orden, sino que quebraron la sintaxis, y hasta la prosodia quedó manca formando escondite para la analogía y haciendo de la ortografía un capricho singular.

Sin embargo, en esta sinrazón, hay motivos ambientales, no justificados; pero los hay, cuales son el desbarajuste de órdenes en que se ha venido perdiendo el hombre, anonadándose en superficies marañosas y agarrándose de lo que le ha trastrocado el sentido de responsabilidad, por lo que sólo las grandes almas y mentes, se adentran en los profundos misterios para sacar de ellos alimentos de superación vital.

El precursor de la nueva forma, está limpio en este momento, motorizado y dinámico, así como esencial al remontarse a dominios cósmicos, cuando está tronando con su trompeta vicentina.

Padre del Futurismo, completamente individual en su poesía, hendedor de horizontes por donde se escapaba del presente, al mirar porvenires, estaba, estuvo, está golpeando con su báculo de paralítico, este Whitman irreponible, las puertas de la eternidad.

Juan Ficipe Toruño, San Salvador, El Salvador. 